\title{
$\mathrm{Ku}$-대역 $50 \mathrm{~W}$ 급 $\mathrm{GaN} \mathrm{HEMT}$ 내부 정합 전력증폭기
}

\section{Ku-Band 50-W GaN HEMT Internally-Matched Power Amplifier}

\author{
김세일 · 이민표 · 홍성준 · 임준수 · 김동욱
}

Seil Kim $\cdot$ Min-Pyo Lee $\cdot$ Sung-June Hong $\cdot$ Jun-Su Lim $\cdot$ Dong-Wook Kim

요 약

본 논문에서는 Wolfspeed社의 CGHV1J070D GaN HEMT를 사용하여 Ku-대역에서 동작하는 $50 \mathrm{~W}$ 급 내부 정합 전력증 폭기를 설계하고 제작하였다. 전력 트랜지스터를 구성하는 단위 트랜지스터 셀의 출력 신호 간 크기와 위상을 맞추기 위해 슬릿과 비대칭 T-junction을 입출력 정합회로에 사용하였다. 비유전율이 40과 9.8인 두 종류의 박막 기판을 사용하여 제작된 내부 정합 전력증폭기는 펄스 주기 $330 \mu \mathrm{s}$, 듀티 $6 \%$ 의 펄스 모드 조건에서 전력 성능이 측정되었으며, 16.2 $16.8 \mathrm{GHz}$ 에서 $50 \sim 73 \mathrm{~W}$ 의 포화 출력 전력과 $35.4 \sim 46.4 \%$ 의 드레인 효율, $4.5 \sim 6.5 \mathrm{~dB}$ 의 전력 이득을 보였다.

\section{Abstract}

In this paper, a Ku-band 50-W internally-matched power amplifier is designed and fabricated using a CGHV1J070D GaN HEMT from Wolfspeed. To obtain the same magnitudes and phases for the output signals of the unit transistor cells, which constitute a power transistor, a slit pattern and an asymmetric T-junction are used in the input and output matching circuits. The internally-matched power amplifier is fabricated on two different thin-film substrates with relative dielectric constants of 40 and 9.8 , respectively, and is measured under pulsed conditions with a pulse period of $330 \mu \mathrm{s}$ and a duty cycle of $6 \%$. The measured results show a maximum output power of $50 \sim 73 \mathrm{~W}$, a drain efficiency of $35.4 \sim 46.4 \%$, and a power gain of $4.5 \sim 6.5 \mathrm{~dB}$ from 16.2 to $16.8 \mathrm{GHz}$.

Key words: GaN, HEMT, Power Amplifier, Internally-Matched, Ku-Band

\section{I. 서 론}

최근의 레이다 시스템은 높은 출력을 내기 위해 고출 력의 고체전자소자 전력증폭기(solid state power amplifier: $\mathrm{SSPA}$ )를 주로 사용하고 있다 ${ }^{[1]}$. SSPA에 사용되는 여러 반도체 소자들 중에서 큰 항복 전압과 높은 전자 이동 속 도, 그리고 우수한 열 전도도를 가지면서 초고주파 영역 에서도 큰 출력 전력과 우수한 효율 특성을 가지는 $\mathrm{GaN}$
HEMT가 각광을 받고 있으며, 이를 이용한 고출력 전력 증폭기 연구 또한 활발하게 진행되어 왔다 ${ }^{[2],[3]}$.

본 논문에서는 Wolfspeed社의 CGHV1J070D GaN HEMT 와 박막공정을 사용하여 $\mathrm{Ku}$-대역 내부 정합 전력증폭기 를 설계 및 제작하였으며, 전력 트랜지스터를 구성하는 각각의 단위 트랜지스터 셀 사이의 신호 크기와 위상을 동일하게 유지하기 위해 슬릿 구조와 비대칭 전력합성 $\mathrm{T}$-junction 구조를 활용하였다.

\footnotetext{
「이 논문은 2018년도 충남대학교 학술연구과제의 지원을 받아 수행되었음.」

충남대학교 전파정보통신공학과(Department of Radio \& Information Communications Engineering, Chungnam National University)

• Manuscript received November 12, 2018 ; Revised December 14, 2018 ; Accepted December 25, 2018. (ID No. 20181112-01S)

· Corresponding Author: Dong-Wook Kim (e-mail: dwkim21c@cnu.ac.kr)
} 


\section{II. 전력증폭기 설계}

\section{2-1 전력증폭기 소자 선정}

본 논문에서 사용된 GaN HEMT 소자는 Wolfspeed社의 CGHV1J070D로 열 전도도가 높은 $\mathrm{SiC}$ 기판에 $0.25 \mu \mathrm{m}$ 공정으로 제작되었으며, $800 \mu \mathrm{m} \times 4,800 \mu \mathrm{m}$ 의 크기, 18 $\mathrm{GHz}$ 까지의 동작 주파수, 트랜지스터 기준 $70 \mathrm{~W}$ 의 높은 포화 출력 전력을 갖는 소자로 $\mathrm{Ku}$-대역에서 $50 \mathrm{~W}$ 이상의 출력 전력을 얻기 위해 선정되었다. 그림 1 은 칩의 실제 사진이며, 소자의 제원을 표 1 에 나타내었다 ${ }^{[4]}$.

\section{2-2 전력증폭기 소자 분석}

Keysight社의 ADS를 통해 CGHV1J070D의 모델을 분 석하고, 소스-풀 및 로드-풀 시뮬레이션을 수행하였다. 소 자는 $V_{d s}=40 \mathrm{~V}, I_{d s}=400 \mathrm{~mA}$ 조건에서 시뮬레이션을 진행 하였으며 그림 2에 최대 가용 이득과 안정도 지수 $k$ 값을 나타내었다. 시뮬레이션 결과, $16.5 \mathrm{GHz}$ 에서 $12.8 \mathrm{~dB}$ 의 최대 가용 이득과 $12.9 \mathrm{GHz}$ 부터 1 이상의 안정도 지수 $k$ 를 보였다.

그림 3은 드레인 효율 $(\mathrm{DE})$ 과 출력 전력(Pdel)의 등고선 도를 보여주고 있으며, $16.5 \mathrm{GHz}$ 에서 최대 $65 \mathrm{~W}$ 의 최대 출력 전력과 $51 \%$ 의 효율을 보였다. Wolfspeed社의 r7 모델에

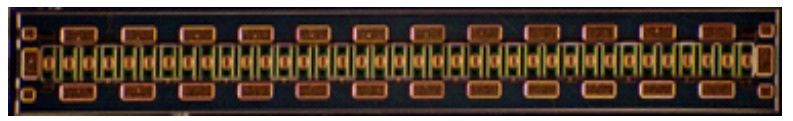

그림 1. Wolfspeed社의 CGHV1J070D

Fig. 1. CGHV1J070D of Wolfspeed.

표 1. CGHV1J070D 소자 제원

Table 1. Device specifications of CGHV1J070D.

\begin{tabular}{|c|c|}
\hline Parameters & Specifications \\
\hline Operating frequency & $10 \mathrm{MHz} \sim 18 \mathrm{GHz}$ \\
\hline Saturated output power & $70 \mathrm{~W}$ \\
\hline Power-added efficiency & $60 \% @ 10 \mathrm{GHz}$ \\
\hline Small signal gain & $17 \mathrm{~dB} @ 10 \mathrm{GHz}$ \\
\hline Operation voltage & $40 \mathrm{~V}$ \\
\hline Size & $800 \mu \mathrm{m} \times 4,800 \mu \mathrm{m}$ \\
\hline
\end{tabular}

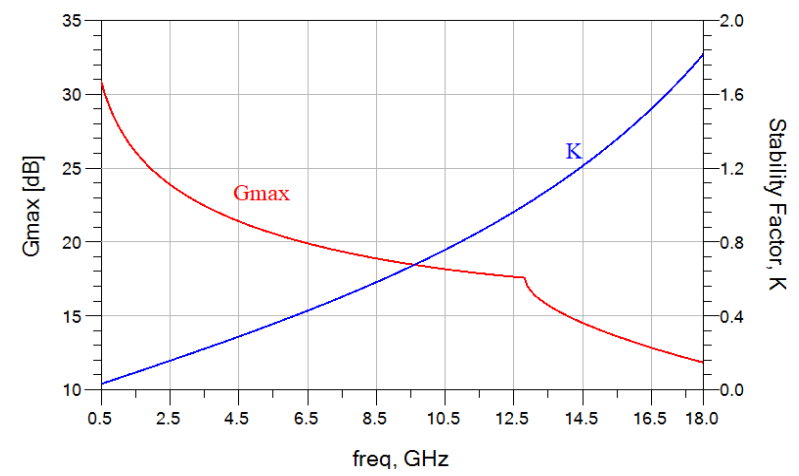

그림 2. 최대 가용이득과 안정도 지수 $k$

Fig. 2. Maximum available gain and stability factor $k$.

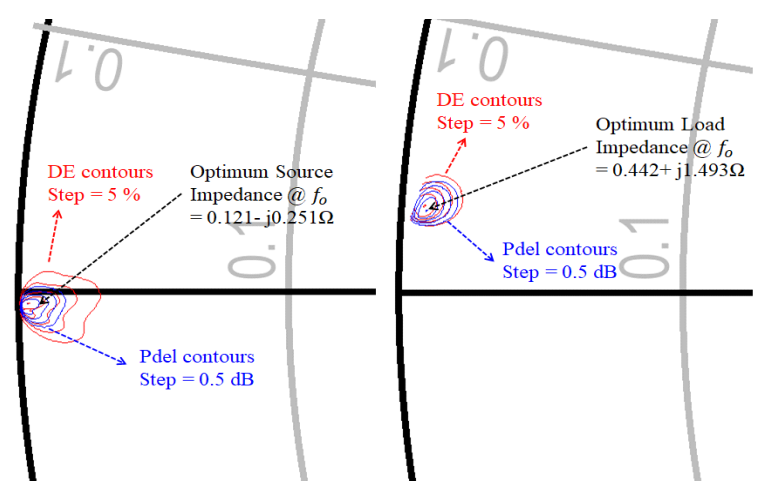

그림 3. 소스-풀 및 로드-풀 시뮬레이션 결과

Fig. 3. Source-pull and load-pull simulation results.

대해 소스-풀과 로드-풀 시뮬레이션을 통해 추출한 최적 임피던스는 $16.5 \mathrm{GHz}$ 에서 각각 $Z_{S}=0.120-j 0.251 \Omega$, $Z_{L}=0.442+j 1.493 \Omega$ 의 낮은 임피던스 값을 보였다.

\section{2-3 입출력 정합회로 설계}

제작에 사용된 트랜지스터의 최적 정합 임피던스는 매 우 작은 값을 가지기 때문에 대역폭을 확보하고 정합 회 로의 크기를 줄이기 위해 40 과 9.8 의 비유전율을 갖는 티 탄산염과 알루미나 재질의 기판을 사용하여 입출력 회로 를 설계하였다.

높은 출력을 내는 증폭기를 설계하기 위해선 전력 트 랜지스터를 구성하는 각각의 단위 트랜지스터 셀들이 동 일한 최적 임피던스를 부하로 가지도록 입출력 정합 회 로를 설계하여야 한다. 따라서 단위 트랜지스터 셀의 출력 
신호가 동일한 크기와 위상을 가지도록 정합 회로를 설 계하였다. 포트 1 3에서 정합 회로를 들여다 볼 때 같은 임피던스를 갖도록 선로에 슬릿를 주고, 포트 1 3과 포 트 4 6을 서로 맞추기 위해 비대칭 구조를 적용하였다 ${ }^{[5]}$. 입출력 정합 회로 모두 최외각에 위치한 트랜지스터 셀 (포트 1 3) 간의 임피던스를 맞추기 위해 짧은 선로 길이 와 슬릿을 티탄산염 기판에 형성하였다. 알루미나 기판에 서는 선로의 폭과 길이, T-junction의 중심 위치를 조절하여 크기와 위상을 맞추었다. 그림 4는 슬릿과 비대칭 $\mathrm{T}-$ junction을 적용된 정합 회로를 보여주고 있으며, 최종 설 계된 정합 회로의 임피던스 궤적을 그림 5에 나타내었다.

\section{III. 전력증폭기 제작 및 측정}

\section{3-1 전력증폭기 제작}

전력증폭기의 방열을 위해 제작된 $\mathrm{CuW}$ 재질의 캐리어

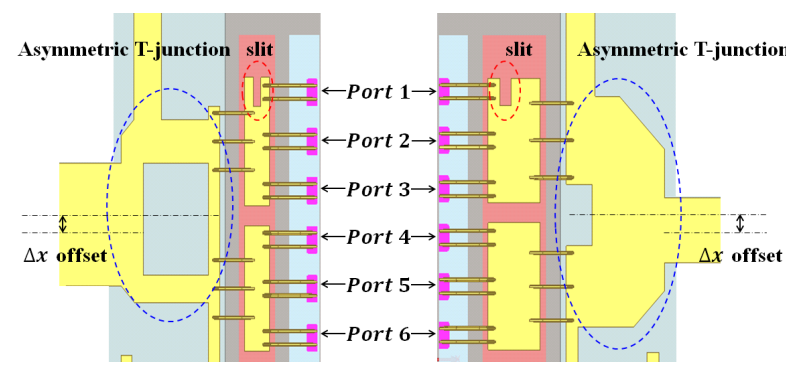

그림 4. 슬릿과 비대칭 T-junction이 적용된 정합 회로

Fig. 4. Matching circuit with a slit and an asymmetric Tjunction.

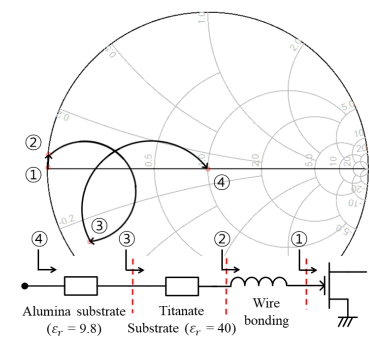

(a) 입력 임피던스 궤적

(a) Input impedance trace

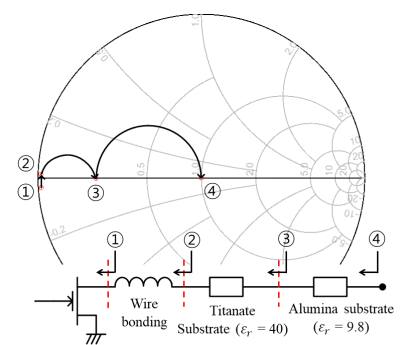

(b) 출력 임피던스 궤적

(b) Output impedance trace
그림 5. 입출력 정합회로의 임피던스 궤적

Fig. 5. Impedance traces of input and output matching circuits.
에 $\mathrm{GaN} \mathrm{HEMT} \mathrm{칩과} \mathrm{2종의} \mathrm{박막기판에} \mathrm{제작된} \mathrm{입출력} \mathrm{정}$ 합회로를 $\mathrm{AnSn}(80 / 20)$ 유테틱(eutectic) 공정을 사용하여 부착하였으며, $1 \mathrm{mil}$ 웻지(wedge) 와이어 본딩으로 칩과 정합 회로, 외부 $\mathrm{PCB}$ 를 연결하였다. 그림 6 은 제작된 전 력증폭기의 사진을 보여주고 있다.

\section{3-2 전력증폭기 측정}

제작된 전력증폭기는 드레인 전압 $40 \mathrm{~V}$, 바이어스 전 류 $400 \mathrm{~mA}$ 조건에서 측정되었다. 그림 7은 제작된 전력 증폭기의 $S$-파라미터 측정 결과(실선)와 시뮬레이션 결과

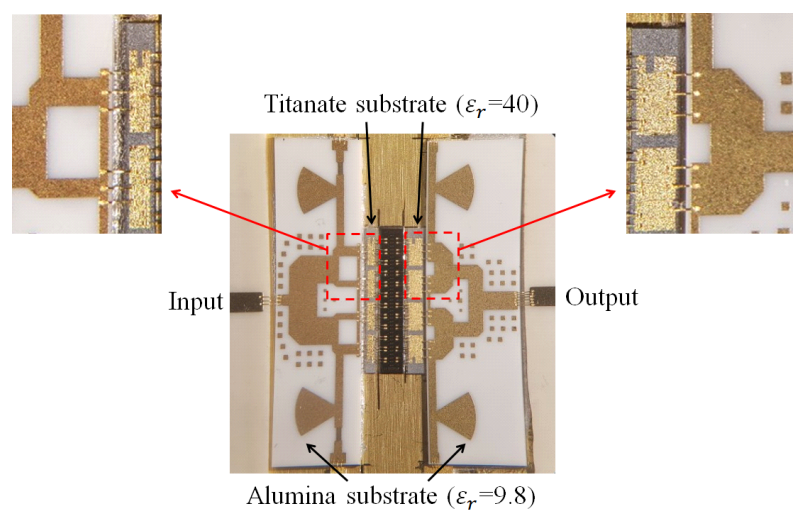

그림 6. 제작된 내부 정합 전력증폭기

Fig. 6. Fabricated internally-matched power amplifier.

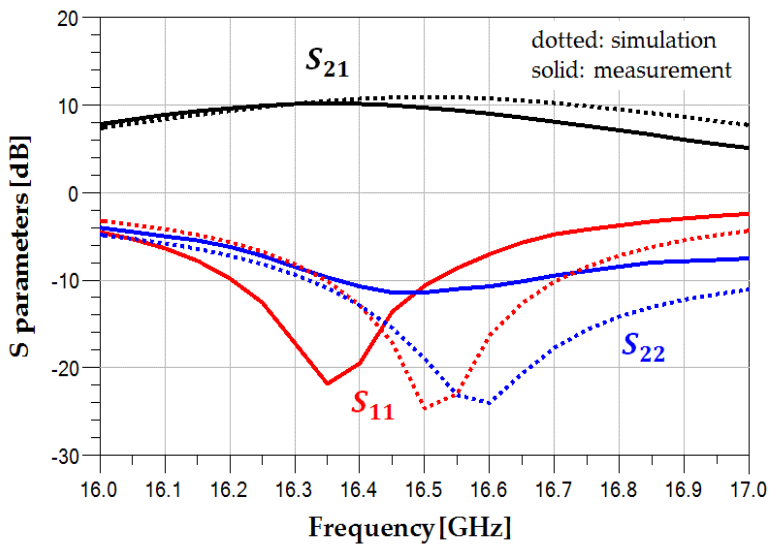

그림 7. $S$-파라미터 측정 및 시뮬레이션 결과(실선: 측정, 점선: 시뮬레이션)

Fig. 7. Measured and simulated $S$-parameter results(solid line: measurement, dotted line: simulation). 
(점선)를 비교하였다. $16.2 \sim 16.8 \mathrm{GHz}$ 에서 측정된 소신호 이득 $\left(S_{21}\right)$ 은 $7.2 \mathrm{~dB}$ 이상으로 측정되었으나, 입력 반사손 실의 주파수 하향 이동으로 인해 시뮬레이션 결과와 비 교할 때 최대 $2 \mathrm{~dB}$ 감소한 모습을 보였다. $16.2 \sim 16.8 \mathrm{GHz}$ 에서 측정된 전력증폭기의 출력 전력 특성을 그림 8 에 나 타내었다. 측정에 사용된 커넥터와 외부 $\mathrm{PCB}$ 의 손실은 제외하였다. 그림 $8(\mathrm{a})$ 는 $16.5 \mathrm{GHz}$ 에서 측정된 전력 특성 으로 출력 전력에 따른 전력 이득과 드레인 효율을 보여 준다. 출력 전력은 $48.1 \mathrm{dBm}(64.5 \mathrm{~W})$ 으로 이때의 전력이 득과 드레인 효율은 각각 $6.0 \mathrm{~dB}$ 와 $42.6 \%$ 의 값을 보였다. 그림 8(b)는 주기 $330 \mu \mathrm{s}$, 듀티 사이클 $6 \%$ 를 갖는 펄스 입력 조건일 때 $16.2 \sim 16.8 \mathrm{GHz}$ 에서 측정된 포화 출력 전

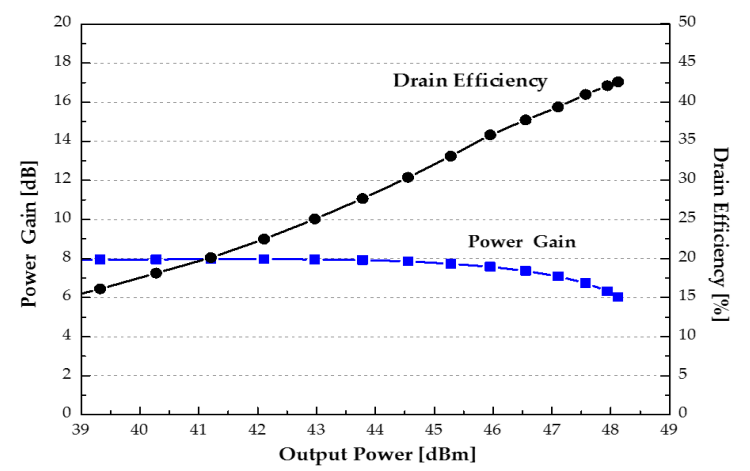

(a) $16.5 \mathrm{GHz}$ 에서의 출력 전력에 따른 전력 성능 특성

(a) Power performance with output power at $16.5 \mathrm{GHz}$

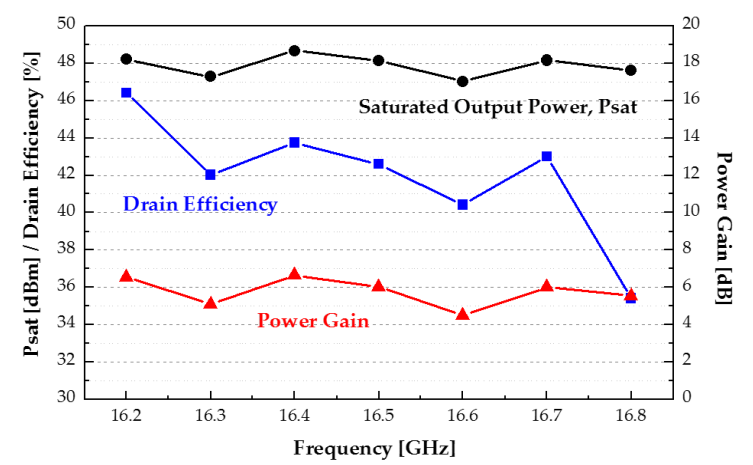

(b) 주파수에 따른 출력 전력 특성

(b) Output power performance with input frequency

그림 8. 제작된 전력증폭기의 측정된 출력 전력 특성

Fig. 8. Measured output power performance of the fabricated power amplifier.
력, 드레인 효율 및 전력 이득을 보여주고 있다. 측정 결 과, 50 73 W의 출력 전력을 보였으며, 이때 드레인 효율 은 35.4 46.4\%를 보였고, 포화 출력 조건에서 4.5 6.5 $\mathrm{dB}$ 의 전력 이득을 얻었다.

\section{IV. 결 론}

본 논문에서는 Wolfspeed社의 CGHV1J070D를 사용하 여 $\mathrm{Ku}$-대역에서 동작하는 $50 \mathrm{~W}$ 급 내부 정합 전력증폭기 를 설계 및 제작하였다. 전력 트랜지스터의 단위 트랜지 스터 셀 간 출력 신호의 크기와 위상을 동일하게 유지하 기 위해 슬릿과 비대칭 T-junction 구조를 입출력 정합 회 로에 적용하였다. 제작된 전력증폭기는 주기 $330 \mu \mathrm{s}$, 듀티 $6 \%$ 를 갖는 펄스 입력 전력 조건일 때 $16.2 \sim 16.8 \mathrm{GHz}$ 에 서 50 73 W의 출력 전력, $35.4 \sim 46.4 \%$ 의 드레인 효율, $4.5 \mathrm{~dB}$ 이상의 전력 이득 특성을 보였다. 제작된 전력증폭 기는 높은 출력을 요구하는 $\mathrm{Ku}$-대역의 레이다 시스템 및 다양한 응용 시스템에 활용될 수 있을 것으로 기대된다.

\section{References}

[1] 이상홍, 김성일, 민병규, 임종원, 권용한, 남은수, "차 세대 $\mathrm{GaN}$ 고주파 고출력 증폭기 기술 동향," 전자통 신동향분석, 29(6), pp. 1-13, 2014년 12월.

[2] D. W. Kim, "An output matching technique for a GaN distributed power amplifier MMIC using tapered drain shunt capacitors," IEEE Microwave and Wireless Components Letters, vol. 25, no. 9, pp. 603-605, Sep. 2015. [3] 강현석, 이익준, 배경태, 김세일, 김동욱, "S-대역 $300 \mathrm{~W}$ 급 GaN HEMT 고조파 튜닝 내부 정합 전력증폭기," 한 국전자파학회논문집, 29(4), pp. 290-298, 2018년 4월.

[4] Wolfspeed. "GaN HEMT CGHV1J070D," 2017. Available: http://www.wolfspeed.com.

[5] K. Mori, J. Nishihara, H. Utsumi, A. Inoue, and M. Miyazaki, "X-band $14 \mathrm{~W}$ high efficiency internally-matched HFET," in 2008 IEEE MTT-S International Microwave Symposium Digest, Atlanta, GA, Jun. 2008, pp. 315-318. 